University of East London Institutional Repository: http://roar.uel.ac.uk

This paper is made available online in accordance with publisher policies. Please scroll down to view the document itself. Please refer to the repository record for this item and our policy information available from the repository home page for further information.

To see the final version of this paper please visit the publisher's website.

Access to the published version may require a subscription.

Author(s): Lane, Pauline., Tribe, Rachel.

Article Title: Unequal Care: An Introduction to Understanding UK Policy and the Impact on Asylum-Seeking Children

Year of publication: 2006

Citation: Lane, P., Tribe, R. (2006) " Unequal Care: An Introduction to

Understanding UK Policy and the Impact on Asylum-Seeking Children" International Journal of Migration, Health and Social Care 2 (2) 7-14

Link to published version:

http://pierprofessional.metapress.com/content//6267667444k7861/

DOI: (not stated)

ISSN: 1747-9894

Publisher statement:

http://www.pavpub.com/pavpub/journals/guidelines/HCS quidelines.pdf

Information on how to cite items within roar@uel:

http://www.uel.ac.uk/roar/openaccess.htm\#Citing 


\title{
Unequal Care: An Introduction to Understanding UK Policy and the Impact on Asylum-Seeking Children
}

\author{
Pauline Lane \\ Department of Public Health, West Norfolk PCT \\ Rachel Tribe \\ Reader, School of Psychology, University of East London
}

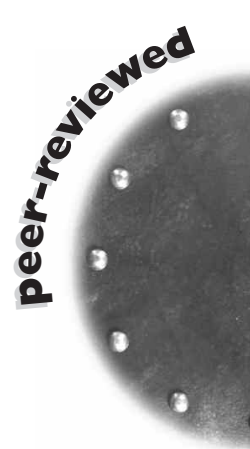

\begin{abstract}
This paper identifies the major relevant legislation and procedures which affect health and social care provision for asylum-seeking children in the UK. It discusses some of the dilemmas asylumseeking children may experience, as well as issues that practitioners may need to consider to ensure that services are appropriate, accessible and non-stigmatising. The paper also identifies the different 'categories' of asylum-seeking children who are supported under different sections of the Children Act and how they can result in unequal levels of social care, and identifies some positive practice for children who have been trafficked.
\end{abstract}

\section{Key words}

asylum-seeking children; Children Act; trafficked; unaccompanied; mental health; holistic.

\section{Introduction}

Most asylum-seeking children do not choose to leave their homelands, but are forced to make dramatic life changes due to decisions and actions of parents and other adults (Miller, 1999). Research suggests that, in contrast with families who have chosen to migrate for economic reasons, asylum-seeking and refugee children may be exposed to a wide range of traumatic incidents and losses before their arrival in the UK, as well as facing a range of dilemmas and difficult experiences during the process of seeking refuge (Kohli \& Mather, 2003; Richman 1998).The special needs of asylum-seeking and refugee children and young people have been recognised in international and national law.

The 1951 UN Convention Relating to the Status of Refugees is the key legal document defining who is a refugee, their rights and the legal obligations of states. While all legal provisions of the 1951 Convention relating to the status of refugees, and in particular the principle of non-refoulement, apply to refugee children, there are no specific provision for children in this Convention. However, the UN General Assembly has also adopted the UN Convention on the Rights of the Child (UNCRC) of 1989. By ratifying this instrument, national governments have committed themselves to protecting and ensuring children's rights, and have agreed to hold themselves accountable for this commitment before the international community. The 1989 UNCRC does not give enforceable rights directly to individual children and young people, but imposes obligations on states to bring their rights into national law. The UK ratified the UNCRC in 1991, and many of the key themes are embraced by UK legalisation.

In the UK, the Children Act 2004 provides the legislative foundation for caring for all children, including asylum-seeking and refugee children, and the needs and wishes of each child should be at the centre of any decision-making. However, asylum-seeking children in the UK do not all receive the same care, and this can have an impact on a child's well-being. In particular, a child whose age is disputed by the Home Office, children who are held in detention and children who have been trafficked are especially vulnerable. This paper identifies how separated asylum-seeking children are cared for under different sections of the Children Act and how this results in different levels of care. Some of these separated children will have been trafficked into the UK, and practitioners need to be aware of their specific needs, and plan for their care and protection. 


\section{Relevant legislation and policies: inconsistencies in support}

There are no exact figures on the number of young asylum-seeking, refugee and separated children in the UK, but estimates suggest that there are approximately 24,500 under 16 years old seeking asylum (Commission for Social Care Inspection, 2005). The most vulnerable groups of these young people are unaccompanied (separated) children. Between 6,000 and 7,000 unaccompanied asylum-seeking children are supported by social services departments in England and Wales (Wade et al, 2005), but this may not be the full number, as many are not known to social services because they have been trafficked into the UK as part of the sex industry (Somerset, 2004).

Whether a child seeks asylum as part of a family or alone will influence the care and support available to the child in the UK. Children who arrive as part of a family make a claim for asylum to the Immigration and Nationality Directorate (IND) through a principal claimant (usually a parent or older sibling). Families who are unable to support themselves can apply for National Asylum Support Service (NASS), and will be dispersed across the UK. Some families will be held in immigration reception centres (sometimes known as detention centres), and dependent children can also be held with one or both of their parents. Research suggests that detention has a negative impact on children and that some children will suffer from depression and changes in behaviour as well as confusion (Crawley \& Lester, 2005; Save the Children, 2005; Lumley, 2003; Rutter, 2003; Harvey, 2000).

However, an increasing number of children are arriving in the UK alone (usually called separated or unaccompanied children). The Home Office Asylum Policy Instruction (API) on Children, issued in April 2006, covers both accompanied and unaccompanied children and young people, and provides guidance to Immigration and Nationality Directorate caseworkers on how to deal with asylum claims from these children and young people. This instruction gives definitions and policy guidance concerning asylum applications from both accompanied and unaccompanied children and young people. While these children can claim asylum in their own right, they are often very vulnerable; some children are at risk from child prostitution or people trafficking.
All separated children should receive services and care under the 1989 Children Act, and social workers should make individual assessments of the services required to care for them, working with the principle of acting in the best interest of the child. However, there are inconsistencies in support and, as a result, separated children do not all receive the same care. Some children will find themselves protected under s.20 of the Children Act 1989, while others will be subject to s.17 of the Children Act 1989. There have been a number of legal and policy developments that provide some clarity on the entitlements of unaccompanied children and young people to social services support. The key developments include the Department of Health and DFES guidance (2000, 2004a, 2004b) for those responsible for unaccompanied children.

S.20 of the Children Act 1989 places a duty on a local authority to 'look after' a child in need (Stanley, 2001). Most separated children and young people should be considered as 'children in need' and registered with, and supported by, the social services departments of the local council where they first present. These children are usually referred to as 'looked after children'. A looked-after child will have a named social worker and clear legal entitlements to things such as a care plan, an independent visitor and support after he or she leaves care. Children cared for under s.20 of the Children Act 1989 have educational entitlements. Generally, these children will be placed in foster care or residential accommodation. Sometimes the children are placed 'out of borough', but the local authority placing the child retains responsibility for the child.

Studies suggest that the majority of 16 - and 17 -yearold unaccompanied asylum-seeking and refugee children are supported under s.17 of the Children Act 1989 (Stanley, 2002; Munoz, 1999). Under s.17, assessments are not necessary, young people are more likely to be placed in bed and breakfast accommodation, and many do not have a named social worker. Since the Hillingdon judgement (2003), s.17 of the Children Act should not be used routinely to provide care for separated children over the age of 16. However, recent research the Save the Children (2005) among 19 local authorities suggested that the majority of children aged 16-17 are now cared for under s.20, but the quality of care to separated children (under s.17 or 20) was raising concern. The poor quality of care was due to lack of capacity and 
resources. The implications are that many young people are left without social work support.

\section{Becoming eighteen}

As a child makes the transition to adulthood (18 years of age), there are both personal and legal transitions that are linked to changes in their entitlement within the asylum process.

Children who are cared for under $\mathbf{5 . 2 0}$ are subject to the Children Leaving Care Act 2000, which was introduced to improve aftercare services. Children who are leaving care within s.20 should be given a Pathway Plan, where their care needs are addressed, irrespective of their immigration status. The plan should take into account an individual's education, housing, health, leisure and support requirements, and should be reviewed every six months.

If a decision has not yet been made by the time they reach 18, they can be subject to detention or dispersal (regardless of the area where they have settled, or the length of time they have been in the UK). If their status is undetermined, they are subject to being returned to their country of origin.

For those who have been looked after by a local authority and the National Asylum Support Service (NASS), there is a transitional arrangement instruction in place to ensure that children who come out of local authority care are moved into the Home Office, or welfare benefits, framework of support. Most young people will receive support and guidance in working through these procedures. As part of the care plan for transition, social workers and other practitioners should prepare young people for a range of possible scenarios, including return to the country of origin.

In contrast to 'looked after' children, those who reach 18 years of age and have been cared for under s.17 are not entitled to support through the Children Leaving Care Act 2000. Generally, NASS policy is to treat these young people as newly arrived asylum seekers. However, if a young person is in the final year of their school examinations (GCSEs and A levels), NASS will consider deferring their dispersal until the exams are over. It is still important to plan for the transition, and social workers and other practitioners should prepare young people for a range of possible scenarios, which may include the possibility of being returned to their country of origin.

Box 1, below, presents a case study as an example of what can happen.

\section{Box I}

Case study: Jamal

While visiting temporary accommodation, a nurse was asked to see Jamal, a young man who had cut his wrists and taken an overdose.

Jamal had previously been fairly settled, and had been attending a college for three years, where he had developed good friendships. He had been seeing the college counsellor, as he was trying to come to terms with witnessing the massacre of his family.

On reaching 18 years of age he was informed that he was being moved out of the area he had lived in for the past three years, where he had friends and support networks. He was not sure where he was being moved to and what support he would receive. Because of the stress over his future, he attempted to commit suicide.

\section{Age disputes}

Separated children often arrive in the UK either without documentation which establishes their age (for example, a valid passport), or with documentation that the Immigration Service regards as suspect. Disputes over age have very significant implications both for the way in which a young person's asylum application is dealt with and for their rights of access to services, support and protection. A young person should have their age 'assessed' by social services to establish whether they should be subject to the adult or child asylum determination procedures, and to determine which agency has responsibility for their accommodation and support while their asylum application is processed.

As a result of age disputes, many young people are incorrectly identified as adults; they are not able to benefit from procedures for child protection, and the principle of 'best interests' of the Children Act is undermined. 
In addition, a separated child whose age is disputed may be held in detention with adults in an immigration reception or removal centre, and is unlikely to be provided with support and social care by social services, or to be able to access education and other training opportunities (Crawley, 2006). In addition, many young people in detention do not know how to access legal support and may find themselves at risk of deportation.

Some of the most vulnerable separated children are those who have been trafficked, who may be forced into prostitution, domestic servitude or organ donation, used in child pornography or sold into marriage. Many of these trafficked children are not visible, and may not have access to help or appropriate care and protection until they escape from their traffickers (see Box 2, below). There is only one safe house nationally for trafficked children (the Poppy Project), and many trafficked children and young people may not know where to get help and protection. Trafficked children should be protected and accommodated under s.20 of the Children Act. The fullest use must be made of the new opportunities for effective inter-agency work with Local Safeguarding Children Boards (LSCBs), which should have an inter-agency strategy and protocols in place for early identification and notification to the relevant agencies of potential victims as they arrive. Children can only be safeguarded properly if the key agencies work effectively together. LSCBs are designed to help ensure that this happens. They will put the current area child protection committees (ACPCs) on a statutory footing.

\section{Box 2}

Client study: Maria

Maria was trafficked into the UK from Uganda, and arrived as a separated young person. She had been raped en route to the UK, and when it was found that she was pregnant from the rape, her social worker supported her through an abortion. However, despite the rape, Maria was not tested for HIV until nearly a year later. Shortly before her 18th birthday she was diagnosed as HIV positive. Her solicitor unsuccessfully lodged a fresh human rights claim (ss.3 and 8 of the European Convention on Human Rights), and she was deported back to Uganda.
There is little statutory guidance on supporting the needs of trafficked children, but UNICEF recommends that they should be placed in safe house accommodation with 24-hour supervision, with support and access to medical care. Without the security of a safe house, trafficked children and young people are vulnerable to being snatched back by their traffickers. It is important that they should have only supervised telephone access so they cannot contact their trafficker.Trafficked children should be offered counselling, education and training opportunities, legal support, awareness-raising about trafficking, and opportunities for social re-integration. These children and young people are highly unlikely to reveal what has happened to them when they initially come into contact with the authorities or nongovernmental organisations. This is for a variety of reasons. They may fear retaliation from traffickers against themselves or their families, or be unwilling to discuss what has happened to them because of trauma, shame, distrust of authorities and/or fear that they will be prosecuted or deported. Trafficked children and young people may require a period of reflection in which they can receive assistance, recover from their traumatic experiences and make an informed decision about whether they wish to co-operate with the authorities in prosecuting the traffickers. As children and young people are likely to be in fear of the traffickers, they may be worried not just about their own safety but also that of their families. Such justified fear may lead them to abscond from care.

\section{Assessment of asylum-seeking children}

It is important to ensure that children and their families are registered as soon as possible with appropriate health professionals such as GPs, midwives and health visitors. In most cases health assessments are conducted in induction centres, and each asylum seeker residing in an induction centre will be issued with a national hand-held record. (These records can be ordered or downloaded from the Department of Health at www.dh.gov.uk/ PolicyAndGuidance/International/AsylumSeekersAnd RefugeesGeneralArticle/fs/en?CONTENT_ID $=4080751 \&$ $\mathrm{CHK}=\mathrm{Vw} 8 \mathrm{xyG}$.) The information carried in the handheld record is designed to improve continuity of care for asylum seekers until they are registered with a GP. Practitioners need to be aware that children and young 
people are often subject to constant assessment, being asked the same questions repeatedly. In line with good practice guidelines and the Every Child Matters policy, good assessment should provide a basis for meeting children's and young people's needs, and service planning should be grounded in an understanding of the child's needs, aspirations and wishes, which should be central to their care planning. An essential part of assessment, service provision and good mental health care is good communication, especially as language is one of the main tools in the therapeutic encounter. Many asylum seekers and refugees do not speak English. Interpreters should be provided as required, and practitioners should be trained in working with them; children should never be used to act as interpreters in a health setting (Lane et al, 2006). A good assessment provides a basis for meeting children's needs, and service planning should be grounded in an understanding of the child's needs and aspirations. It is important to listen to children and their families before acting, to ensure that interventions are based on consultation, reflecting what they need and taking into consideration the age and stage of development of the children involved.

Assessment should include identification of the need for early years and school services. Schooling is beneficial in meeting some of the psychosocial needs of asylum-seeking and refugee children, as well as being a tool to assist in their future development (Arnot \& Pinson, 2005), providing protective factors for children's well-being and development (Sinclair, 1998). It also offers a daily structure, purpose and meaning for children, and benefit from learning English, making new friends and learning. Parents and children should be offered advice and information (in their own language) on how to access services, as well as information on matters such as help with buying school uniform, bullying and exam systems. School and early years provision are often the first places where a child with specific needs can be identified, although they may need specialist information and training on the asylum process and where to get additional support for asylumseeking and refugee children.

For separated children, the picture can be complex. As they come to terms with loss of family, friends and culture (Kohli \& Mather, 2003), some children may initially display symptoms of psychological distress, including intrusive flashbacks of the stressful event(s), nightmares, withdrawal and inability to concentrate. However, practitioners need to be wary of pathologising the psychological responses of these young asylum seekers, and it is important not to turn their normal expression of grief and distress into a medical problem (Richman, 1998). Concern at the over-use of clinical discourse in psychosocial interventions in work with children, and at the minimising of the importance of social power, status and children's rights, have been expressed by Veale and Doná (2002). Some young people will be from cultures where mental illness and psychological distress are taboo subjects, and may express their distress through physical symptoms such as headaches, insomnia and stomach aches. Most children will regain normal functioning once their needs for safety and security have been met and developmental opportunities are restored, in a supportive social and community context. The WHO (2000) says that community-based psychosocial care can help prevent psychiatric morbidity and accelerate improvement of people's psychosocial functioning. Access to services such as schooling and leisure, as well as faith groups and refugee community organisations, can play a significant role in the mental well-being of asylum-seeking and refugee children (WHO, 2000).

Some children arriving in the UK may have been tortured or be suffering from previous traumatic experiences. This may be difficult to identify in early assessments, and some of these children may need access to specialist services. However, it should not be assumed that children who have survived these experiences are mentally ill, and not all children will wish for specialist support; torture does not necessarily result in a psychiatric disorder. Remember that expression of distress, anxiety, grief, guilt and shame may be normal responses to highly abnormal experiences. It is important not to turn normal emotional and psychological responses into a medical problem. Many children and young people who are survivors of torture and traumatic events will not wish for mental health support, but may find other mechanism of support and ways of coping; schooling, faith groups and leisure groups may be more familiar and appropriate to their needs. 
It is important to consider the holistic needs of the child and to view their psychological symptoms in the context of their current situation in the UK (seeking asylum in a strange country), as well as their experiences in the country of origin.

Some children will require more specialised interventions to address their suffering and help restore their development and well-being. Practitioners should ensure that asylum-seeking and refugee children with more serious mental health needs are referred to appropriative services (local statutory services such as local child and adolescent mental health teams, or more specialised services such as the Medical Foundation for the Care of Victims of Torture). Unfortunately, there are only a few specialists service providers, and they are unevenly spread across the country.

\section{Promoting the mental health and well-being of separated, refugee and asylum-seeking children and young people}

Most families and young people face huge challenges on arrival in the UK, but often the most urgent needs are practical and legal. A holistic, multi-agency approach is valuable in promoting mental health and well-being. Addressing social concerns actively works to promote mental health and well-being, and could include advice on housing, legal advice and education, as well as community-based interventions such as linking with local community groups and facilities (see Box 3 , below). It is helpful to normalise the family's asylum experience through information in the home languages (oral, visual and text), as well as offering support and advice and access to appropriate support (Miller, 1999). Children's and young people's participation in decisions that affect their lives has a positive effect on their mental health, empowers them and helps them to regain control over their own lives.

Creative opportunities and play are important, and can help children's and young people's emotional wellbeing, releasing tension and anxieties. Having fun and enjoyment can enable children and young people to cope better, and enhance their resilience (McMahon, 1992; Quiroz, 2002). These activities can also provide a validating, normalising effect and can enhance psychological well-being and mental health. For example, art, music and drama offer great potential to newly arrived children and young people; creation of artwork or music can boost the self-esteem of a newly arrived child, especially if they don't speak English and are unable to share their world with other children and young people through their home language. Children and young people can benefit from joining local groups such as sports groups, youth groups, befriending groups and refugee community organisations (Tribe, 2004). However, many asylum-seeking and refugee children and young people are living on very low incomes, which can restrict their access to leisure and recreation opportunities. Practitioners may need to work with other agencies to facilitate access to creative services at special rates, and schools need to be aware that after-school activities involving additional costs (such as sports equipment or instruments) may prohibit some young asylum seekers from accessing these opportunities.

\section{Box 3}

Positive practice: Sheffield family support worker

Every asylum-seeking family attached to the Sheffield Primary Medical Service has a family support worker.These workers have all attended the 'home start' training (which looks at issues relating to being a parent in the UK, and assists in accessing and developing support networks). The workers are often refugees who speak many languages and are a great source of information and contacts; they can also offer friendship. They visit and provide support to newly arrived families, and their role includes things like sorting out practical concerns (such as the whereabouts of the nearest school), travelling with families to places, such as the health centre to show them what to do, helping to find equipment that families need (baby clothes, school books, uniform, toys and access to 'play sacks' for young children), and linking new asylum-seeking families with local community and faith groups. The Children's Fund provides the funding for this project. 


\section{The future}

\section{New asylum model (NAM)}

The Government is in the process of introducing a new system for dealing with asylum applications that involves dividing asylum seekers into separate categories according to the nature of the claim. Under the NAM, each asylum claim will be dealt with by a single 'case worker', who will work out a case management plan for each new claim and follow it through from beginning to end of the process, making decisions and communicating them to the applicant. It is not clear how this will affect children and young people, although they will be defined as a distinctive group of claimants. The Home Office is due to introduce the new asylum model in December 2006.

\section{Planning for the future: dual planning}

Until an asylum claim has been accepted or rejected by the Home Office, children, young people and their families are left feeling that they have an uncertain future. This waiting in limbo can generate considerable stress, but practitioners can help children and their families to plan for different outcomes and make plans for their future. Dual planning is essential, as it helps children and their family prepare for staying in the UK, staying in the UK for a limited period, or returning to the country of orgin. For practitioners working to improve the mental health of asylum-seeking families and their children, it is important to help the family and children to develop personal and family strategies before a decision is made on their asylum claim. This can help families and children feel that they have some control and can plan responsive and purposeful action for the future (National Children's Bureau, 2006).

\section{Conclusion}

This paper has offered an introduction to understanding UK policy and procedures and their potential impact on asylum-seeking children. It has looked at the inconsistencies in the support which is currently available within existing provision. It has also focused attention on some of the issues relating to an asylumseeking child on reaching the age of 18 and adulthood, when this transition will affect both their status and entitlements. Age disputes have been discussed briefly, and some of the difficulties associated with this process reviewed. Short case studies and examples of good practice have been offered throughout this paper. The paper has also made some suggestions for practitioners working with young people and has drawn attention to the specific issues relating to trafficked children. Some information about the assessment of asylum-seeking children and the importance of considering their cultural context, their individual needs and the importance of their voices being heard has been made. The paper has also considered some of the dilemmas which asylumseeking children and practitioners may face, and has discussed the role of dual planning. Further research is needed on the needs of asylum-seeking children which involves them in this process to ensure that their needs are considered and resources are offered in the most appropriate and helpful manner.

\section{References}

Arnot M \& Pinson P (2005) The Education of Asylum-Seeker E Refugee Children:A Study of LEA and School Values, Policies and Practices. University of Cambridge Faculty of Education.

Commission for Social Care Inspection (2005) A Second Joint Chief Inspector's Report on Arrangements for Safeguarding Children. Crown Copyright.

Crawley H (2006) Child First, Migrant Second. London: Immigration Law Practitioners'Association.

Crawley H \& Lester T (2005) No Place for a Child: Children in UK immigration detention: impacts, alternatives and safeguards. London: Save the Children.

Department of Health \& Department for Education \& Skills (2000) Guidance on the Education of Children and Young People in Public Care. LAC (2000) 13. London: DoH \& DfES.

Department of Health \& Department for Education \& Skills (2004a) Unaccompanied Asylum-Seeking Children - Leaving Care Costs. LAC (2004a) 21. London: DoH \& DfES.

Department of Health \& Department for Education \& Skills (2004b) Unaccompanied Asylum-Seeking Children - Leaving Care Costs: 2004-05: additional guidance. LAC (2004) 6. London: DoH \& DfES.

Harvey A (2000) Briefing from the Medical Foundation for the Care of Victims of Torture on the Detention of AsylumSeeking Children and Young People.Available from the Medical Foundation.

Kohli R \& Mather R (2003) Promoting psychosocial well-being in unaccompanied asylum seeking young people in the United Kingdom. Child E Family Social Work 8 (3) 201-12.

Lane P,Tribe R \& Hearsum S (2006 in press) Diverse People with Diverse Needs: A Guidebook for Mental Health Practitioners Working with Asylum Seekers and Refugees. London: Department of Health. 


\section{Unequal Care: An Introduction to Understanding UK Policy and the Impact on Asylum-Seeking Children}

Lumley R (2003) Children in Detention:A Refugee Council policy paper.Available from the Refugee Council.

McMahon G (1992) The Handbook of Play Therapy. London: Routledge.

Miller K (1999) Rethinking a familiar model: psychotherapy and the mental health of refugees. Journal of Contemporary Psychotherapy December 283-306.

Munoz N (1999) Other People's Children:An exploration of the needs and provision for 16 and 17 year old unaccompanied children. London: Guildhall University.

National Children's Bureau (2006) Identifying what works, looking at what constitutes good practice and bow to build upon this.

Quiroz N (2002) Children, organization and recovery in Latin America. Forced Migration Review 15 12-3.

Richman N (1998) Looking before and after: refugees and asylum seekers in the West. In: PJ Bracken \& C Petty (Eds) Rethinking the Trauma of War. London: Save the Children.

Rutter J (2003) Working with Refugee Children. York: Joseph Rowntree Foundation.

Save the Children (2005) No Place for a Child. London: Save the Children Publications.

Sinclair R (1998) The Education of Children in Need. Dartington: Research in Practice/NCB.
Somerset C (2004) Cause for Concern. London: Social Services and Child Trafficking ECPAT UK.

Stanley K (2001) Cold Comfort:Young separated refugees in England. London: Save the Children Fund.

Tribe R (2004) A critical review of the evolution of a multilevel community-based children's play activity programme run by the Family Rehabilitation Centre (FRC) throughout Sri Lanka.Journal of Refugee Studies 17 (1) 114-35.

UNICEF (2005) Information sheet on the protection of trafficked children. www.unicef.org.uk/press/news_detail.asp? news_id=467. Accessed June 62006.

UNICEF Child Trafficking. www.unicef.org.uk/unicefuk/ policies/policy_detail.asp?policy=7. Accessed July 7th 2006.

Veale A \& Doná G (2002) Psychosocial interventions and children's rights: beyond clinical discourse. Peace and Conflict:Journal of Peace Psychology 8 (1) 47-6I.

Wade J, Mitchell F \& Baylis G (2005) Unaccompanied asylumseeking children: the response of social work services. University of York, Social Work Research \& Development Unit.

World Health Organisation (2000) Mental bealth of refugees, internally displaced persons and other populations affected by conflict. www.who.int/hac/techguidance/pht/ mental_health_refugees/en/.Accessed June 62006. 